\title{
DA CINDERELA OUVINTE À CINDERELA SURDA ANÁLISE MULTIMODAL E ENSINO
}

\begin{abstract}
Lorena Poliana Silva Lopes é mestranda pelo Programa de Pós-Graduação em Linguística (PPGL), na Universidade de Brasília (UnB), e é bolsista do CNPq. E-mail: lorenpoliana@gmail.com

\section{Resumo}

O objetivo deste artigo é averiguar como as estruturas composicionais da Gramática Visual (2006) foram empregadas em Cinderela (SOUSA, 2008) e em Cinderela Surda (2011) para produzir sentido e como essa análise promove a leitura e interpretação textual. Nota-se a coerência no emprego dos modos semióticos verbal e não verbal em relação de complementaridade, bem como a sua potencialidade em amplificar os sentidos por meio das integrações estabelecidas.

Abstract

The objective of this article is to ascertain how the compositional structures of Visual Grammar (2006) were employed in Cinderela (SOUSA, 2008) and in Cinderela Surda (2011) to produce meaning, and how this analysis provokes reading and textual interpretation. The coherence in the use of verbal and nonverbal semiotic modes in relations of complementarity, as well as its potentiality in amplifying the senses through the established integrations, is noteworthy.
\end{abstract}

\section{1) Introdução}

Este trabalho tem por objetivo analisar as literaturas "Cinderela", da coleção Clássicos Ilustrados (SOUSA, 2008), e "Cinderela Surda” (2011), à luz da Gramática Visual, de Kress e Van Leeuwen (2006), no que tange às categorias Participante e Composição; e da ADC de Fairclough (2008), de forma teórica e metodológica por meio da análise da intertextualidade, além da produção, distribuição e consumo de textos. Apesar da seleção de duas obras, convém esclarecer que o objetivo aqui não é lançar julgamento de valor, mas analisar como as estruturas composicionais foram usadas pelos produtores para produzir sentido e, a partir disso, observar como a análise de categorias da Gramática Visual pode ser eficiente na promoção da leitura e interpretação textual, sendo que a Gramática Visual se coloca como uma base teórica que examina as relações entre as semioses, ou seja, as maneiras em que elas se comunicam (Kress e Van Leeuwen, 2006). Por fim, propomos uma reflexão quanto à inserção e abordagem dessas obras em contextos de Educação Bilíngue para surdos.

A análise linguística é, por si só, uma atividade complexa e técnica, todavia, para a análise proposta, considerar-se-á que a análise da imagem é de suma importância, assumindo-se que tanto o texto verbal quanto o texto não verbal constroem as narrativas e fornecem pistas para a recepção e interpretação delas. Acreditamos que as ilustrações são parte constitutiva do discurso, não estando, portanto, exclusivamente a serviço da "estética". Assumimos a premissa de que todo texto é, por natureza, multimodal.

Na seção seguinte, abordaremos as concepções teóricas que embasarão as análises e suas reflexões. 


\section{2) Considerações teóricas}

A Semiótica Social é a terceira escola de estudos linguísticos aplicados aos textos multimodais, com ênfase nos processos de produção e recepção do signo. Dessa forma, evidenciam-se suas bases teóricas, as quais são os trabalhos de Halliday (1978), na Linguística Sistêmico-Funcional - LSF, e de Fairclough (2008), na Análise do Discurso Crítica - ADC. De acordo com Hodge e Kress (1988, p.261, apud SANTOS e PIMENTA, 2014, p.298), a semiótica é "o estudo da semiose, dos processos e efeitos da produção, reprodução e circulação de significados em todas as formas, usados por todos os tipos de agentes da comunicação".

A Semiótica Social possui algumas premissas básicas, estruturalmente relacionadas à sua definição. São estas: (i) "o reconhecimento de que, para se compreender os processos e as estruturas da linguagem, é indispensável levar-se em conta sua dimensão social [...]" (VIEIRA e FERRAZ, 2011, p.11); (ii) considera-se, nos estudos, os modos semióticos verbal e não verbal; (iii) defende-se que "a relação entre significante e significado não é arbitrária, mas socialmente motivada e, portanto, permeada por questões ideológicas." (VIEIRA e FERRAZ, 2011, p.114); e, por fim, (iv) utiliza-se o termo "recurso" ao invés de "código", visto que este não satisfaz a realidade dos sistemas semióticos, uma vez que há recursos que não se pautam em prescrições estritas, como os códigos - na Gramática Visual mapeiam-se os significados potenciais desses recursos semióticos (VIEIRA e FERRAZ, 2011).

Como mencionado, a Semiótica Social se pre(ocupa) com os processos de produção e recepção dos signos, vejamos, pois, estes conceitos em Fairclough (2008). A ADC entende a prática discursiva enquanto parte constitutiva da prática social e, dessa forma, a análise de discurso enfoca os processos de produção, distribuição e consumo, sendo que, cada um desses "varia entre diferentes tipos de discurso de acordo com fatores sociais" (FAIRCLOUGH, 2008, p.107). Quanto à produção, “os textos são produzidos de formas particulares em contextos sociais específicos" (FAIRCLOUGH, 2008, p.107), de maneira individual ou coletiva.

Em relação ao consumo, Fairclough diz que "os textos também são consumidos diferentemente em contextos sociais diversos" e que "isso tem a ver parcialmente com o tipo de trabalho interpretativo que neles se aplica [...] e com os modos de interpretação disponíveis" (2008, p.107). Este processo também pode ser individual ou coletivo e, além disso, pode resultar em mudanças nas práticas sociais, como uma mudança de atitude ou de crença. A distribuição, por sua vez, pode ser simples, como uma conversa casual, sem planejamento prévio, ou pode ser complexa, como os discursos do governo, que são produzidos "de forma a antecipar sua distribuição, transformação e consumo, e neles constroem leitores múltiplos." (FAIRCLOUGH, 2008, p.108).

Ainda em relação às práticas sociais enquanto prática discursiva, temos a categoria de análise Intertextualidade, também discutida por Fairclough (2008). Nas obras em questão, observaremos que há intertextualidade, seja constituída no discurso verbal, seja no não verbal. Autores como Kristeva (1967), e Bakhtin (1997) dissertaram sobre o que 
é esse fenômeno. De maneira geral, ambos consideram que não há textos que não se remetem a textos anteriores e que não aludem a textos posteriores. Dessa forma, todo texto é uma colcha de dizeres em algum nível e modo.

Anos mais tarde, Fairclough (2008) contemplou esse fenômeno como uma das categorias de análise de discurso no âmbito da ADC. Para ele, o conceito de intertextualidade aponta para a produtividade dos textos, para como os textos podem transformar textos anteriores e reestruturar as convenções existentes (gênero, discursos) para gerar novos textos (FAIRCLOUGH, 2008, p.135).

Como um dos norteadores deste tipo de análise, temos o seu objetivo que é identificar o que esta intertextualidade está promovendo na constituição do texto em questão e como isso ocorre. No sentido deste último, temos que a intertextualidade pode se delinear de dois modos: pela intertextualidade manifesta, que é aquela marcada e explícita no texto; ou pela intertextualidade constitutiva, também chamada de interdiscursividade, que é aquela em que um texto incorpora outro sem explicitações, ou seja, a "interdiscursividade é uma questão de como um tipo de discurso é constituído por meio de uma combinação de elementos de ordens de discurso" (FAIRCLOUGH, 2008, p.152).

Para a análise aqui proposta nos valeremos do conceito de intertextualidade constitutiva, doravante, interdiscursividade. Esta análise pode se dar via quatro elementos de ordens de discurso, sendo estes o gênero, o tipo de atividade, o estilo, e o discurso. Aqui faremos um recorte, contemplando apenas os elementos "gênero" e "discurso". O gênero é "um conjunto de convenções relativamente estáveis que é associado com, e parcialmente representa, um tipo de atividade socialmente aprovado" (FAIRCLOUGH, 2008, p.161). O gênero implica processos particulares de produção e distribuição-consumo de textos. Já "os discursos correspondem aproximadamente às dimensões do texto, que têm sido discutidas tradicionalmente em termos de 'conteúdo', 'significados ideacionais', 'tópico', 'assunto', e assim por diante”(FAIRCLOUGH, 2008, p.163-164).

Diante deste escopo teórico da ADC, convém abordar que a grande questão é que a Semiótica Social concorda com a ADC no que tange à sua proposta de análise de discurso, porém acrescenta o seu olhar, que é voltado para a multimodalidade, daí se considerar numa análise tanto o modo semiótico verbal quanto o não verbal. É nesta perspectiva que empreenderemos nossa análise. Para esta, selecionamos, dentre várias categorias da Gramática Visual (2006), as categorias "Participantes" e "Composição espacial do significado".

Segundo a Gramática Visual, (KRESS \& VAN LEEUWEN, 1996, apud MAROUN, 2006), “'Participante' é o termo técnico usado para designar objetos e elementos presentes em uma composição gráfico-visual" (MAROUN, 2006, p.61). Estes podem ser separados em (i) participantes representados, que "são os participantes que representam o objeto da comunicação (pessoas, lugares, coisas...) [...] sobre os quais se 
está falando, escrevendo e produzindo imagens.” (MAROUN, 2006, p.61); e (ii) participantes interativos, que são os receptores, para os quais se dirige a mensagem.

A categoria composição espacial do significado "pode relatar significados representacionais e interativos entre os elementos" (MAROUN, 2006, p.63) por meio de três parâmetros:

(1) Valor da informação: "refere-se ao lugar dos elementos (participantes, sintagmas que se relacionam entre si e com o viewer/leitor), como a localização da informação se à direita ou à esquerda, no alto ou embaixo, no centro ou na margem." (MAROUN, 2006, p.63). É composto pelos princípios:

(1.1) "Dado/Novo": se referem ao valor que é atribuído à informação, considerando-se que, se ela se encontra à esquerda da página, significa que se trata de informação “dada”, já conhecida pelo leitor. Se ela se encontra à direita, significa que se trata de informação "nova", não conhecida pelo leitor - a que exige maior atenção.

(1.2) "Ideal/Real": se referem ao valor que é atribuído à informação, considerando-se que, se ela se encontra acima (superior) na página, significa que é informação idealizada, abstrata (ideal), mais distante da realidade. E, se se encontra abaixo (inferior), significa que é informação concreta, prática, mais específica e detalhada, portanto, mais próxima do real.

(2) Saliência/Projeção: se refere à integração (locação e enfoque) dos elementos que constituem a página, como primeiro e segundo planos, tamanho relativo, contrastes e tonalidades, cores e formas. A projeção não é medida objetivamente, mas é julgada com base nessas pistas visuais (MAROUN, 2006).

(3)Enquadramento (framing): "a presença ou ausência de divisão de molduras (frames) é realizada por elementos que criam linhas divisórias, desconectam ou conectam elementos da imagem, compondo ou significando de forma conjunta ou não." (MAROUN, 2006, p.63)

Na sessão seguinte, tomaremos conhecimento da contextualização histórica das obras em questão, bem como de alguns aspectos relativos à produção e distribuição-consumo delas.

\section{3) Contextualização das obras literárias}

$\mathrm{O}$ conto de fadas Cinderela nem sempre foi como popularmente o conhecemos. $\mathrm{O}$ original, também chamado de $\mathrm{O}$ sapatinho de vidro, possui um enredo diferente das versões ocidentais:

A primeira Cinderela que conhecemos chamava-se Yeh-hsien, e sua história foi registrada por TuanCh'engshih por volta de 850 d.C.Yeh-hsien usava vestido feito de plumas de martim-pescador e minúsculos sapatos de ouro. Ela triunfa sobre sua madrasta e a filha desta, que são mortas a pedradas. Como as Cinderelas ocidentais, Yeh-hsien é uma criatura humilde, que faz os serviços domésticos e sofre tratamento humilhante nas mãos da madrasta e da filha desta. Sua salvação aparece na forma de um peixe de três metros de comprimento que a cumula de ouro, pérolas, vestidos e comida. As Cinderelas que 
seguem nas pegadas de Yeh-hsien encontram sua salvação na forma de doadores mágicos. (TATAR, 2013, p.44)

Em uma edição comentada e ilustrada dos contos de fadas, Tatar (2013) empreende uma incursão histórica e crítica acerca dos contos de fadas e de seu status literário. Em suas palavras,

Os contos de fadas, outrora narrados por camponeses ao pé da lareira para afugentar o tédio dos afazeres domésticos, foram transplantados com grande sucesso para o quarto das crianças, onde florescem na forma de entretenimento e edificação. Esses contos, que passaram a constituir um poderoso legado cultural transmitido de geração em geração, fornecem mais que prazeres amenos, enlevos encantadores e deleites divertidos. [...] Despertando a um só tempo medo e alumbramento, os contos de fadas atraíram ao longo dos séculos tanto defensores entusiásticos, que celebram seus encantos vigorosos, quanto críticos severos, que deploram sua violência. (TATAR, 2013, p. 9-10)

O percurso que não se pode perder de vista é que, "os contos de fadas que lemos hoje para as crianças tiveram suas origens numa cultura em que histórias eram contadas entre adultos" (TATAR, 2013, p.9), além de situacionalmente estarem localizadas em outro tempo e espaço. De fato, os contos originais são constituídos por outros signos e outras "morais" - ou a falta dela - condizendo, todavia, à sua situacionalidade.

Por se achar dentre os críticos quem deplorasse o aspecto violento e julgasse a "moral" das histórias como inadequada e incoerente com os ensinamentos dos pais e os bons costumes socialmente aceitos, as releituras dos contos de fadas sofreram alterações no sentido de se atualizarem no tempo e espaço e de se adequarem aos novos contextos culturais e linguísticos. Tanto a obra Cinderela, da coleção "Clássicos Ilustrados", quanto Cinderela Surda, fazem parte dessa gama de releituras ocidentais, trazendo no enredo uma moral desejada, com uma orientação clara, positiva, e de fácil compreensão.

$\mathrm{Na}$ primeira, exemplos disso são a capacidade que Cinderela tem de permanecer com esperança e a sua sorte em se casar com o príncipe e viver feliz para sempre, desaguando, portanto, nas ideias de que "vale a pena ser bom" e de que "o bem sempre vence o mal". Vale ressaltar que há três claras diferenças nessa edição em relação às outras popularmente difundidas na atualidade: (i) na condensação da história foi eliminada a clássica cena em que Cinderela vai ao baile via Carruagem, que antes era uma abóbora; (ii) ao invés de ser uma fada a realizar seus desejos, quem o faz é uma ave; e (iii) quanto às ilustrações, foram feitas por Maurício de Sousa, com seus personagens da Turma da Mônica, fazendo alusão ao "amor" dos personagens Cebolinha e Mônica - marca da intertextualidade.

Na segunda, a moral está a serviço de parâmetros orientados por outra cultura, a cultura surda. Nesta releitura, Cinderela é uma jovem surda francesa, usuária de Língua de Sinais Francesa, a qual pôde aprender na sua infância. Apesar disso, ela vive o dilema da restrição comunicativa em casa, pois sua família - a madrasta e as irmãs - pouco sabem dessa língua. A convivência em casa é difícil, pois essa família é ruim e a submete a todos os serviços domésticos. Sua salvação é encontrar um príncipe surdo e também usuário da 
LSF, para partilhar com ela sua identidade surda. De maneira condizente, Cinderela, ao sair do baile, não perde um sapatinho de cristal, mas uma de suas luvas - símbolo importante para a comunidade surda, pois remete aos seus movimentos de lutas e também ao direito de utilizar Língua de Sinais (KARNOPP, 2006).

Esta versão foi contada e recontada pelos surdos em suas práticas sociais e os autores do livro tiveram a vontade de registrá-la. Segundo eles,

Este livro foi construído a partir de uma experiência visual, com imagens, com o texto reescrito dentro da cultura e identidade surda e da escrita da língua de sinais, conhecida também como signwriting. (SILVEIRA et al, 2011, p.5).

A presença do signwriting deve ser concebida como um fator positivo que, além de delinear uma adequação linguística em relação ao público alvo, contribui de maneira impar às experiências literárias dos leitores, considerando que o momento de leitura dessa escrita pode se tornar um importante gerador de "reações", como a memória que os leitores guardarão ao longo de muitos anos ou da vida.

Cada experiência de leitura pode gerar diferentes tipos de "reações" e, segundo Tatar (2013), os geradores podem ser as imagens que mais chamaram a atenção do leitor, as quais ele guardará em sua memória, ou a leitura realizada em voz alta ou ouvida, bem como suas diferentes tonalidades. Enfim, todos os elementos e as performances que podem envolver a leitura possuem potencial transformador da experiência literária e gerador de reações (como a memória imagética ou sensorial).

Não obstante, é preciso observar que o enredo claramente nos remete ao contexto histórico-social, não tão distante, da educação dos sujeitos surdos quando eles viveram a transição do Oralismo para o Método Francês, em que foi autorizado o uso e o ensino de Língua de Sinais. O cenário, entretanto, era esse (e ainda é em alguns locus sociais): o de uma restrita comunicação entre os surdos e os ouvintes, dentre outros fatores, pela restrição linguística entre eles.

Tal contextualização do gênero contos de fada, quando das obras em questão, desvelam os processos de produção e de distribuição destas, em certo nível. Como já visto, na perspectiva da ADC, a produção é um processo de construção discursiva, individual ou coletivo, pensado e/ou realizado em práticas sociais. Ao olharmos para o gênero contos de fada e identificarmos sua origem, o seu status, sua relevância em um espaço e tempo social, como fizemos acima, estamos olhando para a produção e para o consumo. Este olhar é o que nos permite compreender, por exemplo, a diferença essencial entre o processo de produção da Cinderela original e da Cinderela ocidental, chamada de "clássica", bem como enxergar a justificativa para suas existências, ou seja, o porquê de se fazer releituras.

A primeira tinha compromisso com o entretenimento, a segunda com a educação enquanto moral social e promoção dos "bons costumes" da época. Já, em Cinderela Surda, há um salto nessa abordagem, ainda contemplando o compromisso da segunda, mas lhe acrescendo um viés da crítica social. Para além de servir à "boa educação", se preocupa 
com a justiça social e com a apreciação da cultura surda como discurso particular central desta releitura, representado por meio dos recursos semióticos mobilizados, a fim de registrar e difundir a história da educação dos surdos. Se a luta em Cinderela ocidental está para a dicotomia entre o bem e o mal, a luta em Cinderela Surda está para o fortalecimento de uma cultura de minoria e para o requerimento e promoção de um espaço de fala da comunidade surda.

A distribuição-consumo, nestes casos, se coloca como meio e como fim dessas produções. Enquanto meio, ela é a fase do processo de produção que delineia o modo semiótico e linguístico em que estas releituras serão inseridas nas práticas sociais, sob a perspectiva de sua funcionalidade e seu potencial discursivo para a mudança social. $\mathrm{O}$ produtor, portanto, seleciona a que e a quem a obra serve ou se destina, e como ela será realizada, se de forma oral ou visual, por exemplo. Enquanto fim, é a fase do processo em que se configuram o público-alvo, o leitor/consumidor em potencial e o seu alcance de circulação.

Em Cinderela Clássica, percebemos que a distribuição-consumo, enquanto meio, se revela como uma obra a serviço da educação moral, da educação escrita e da pedagogia, e enquanto fim, se revela como destinada ao público infantil e potencialmente acessível, com grande poder de circulação, visto que se trata de uma produção especial em parceria com o artista Maurício de Sousa, profissional de renome no meio da produção literária e gráfica.

Em Cinderela Surda, percebemos que a distribuição-consumo, enquanto meio, se releva como uma obra a serviço da justiça social e do fortalecimento e visibilidade das minorias. O seu potencial de transformação social, portanto, está em sua escolha temática ao aliar o discurso moral de Cinderela Surda com o discurso particular da cultura surda. Enquanto fim, revela ter como destinatário principal os surdos usuários de LS e de signwriting, mas não só, contemplando os surdos não usuários de LS e/ou de signwriting e também os ouvintes que se interessam pela cultura surda ou participam da comunidade surda.

Para o momento, o olhar crítico acerca dos processos de produção e consumo presentes em toda a contextualização, por exemplo, no que tange às motivações para a construção de releituras do clássico, bem como às diferentes experiências literárias dos leitores, enriquecem as nossas análises:

Os contos de fadas, segundo o ilustrador britânico Arthur Rackham, tornaram-se "parte de nosso pensamento e expressão cotidianos, e nos ajudam a moldar nossas vidas". [...] Quer tenhamos ou não consciência disso, os contos de fadas modelaram códigos de comportamento e trajetórias de desenvolvimento, ao mesmo tempo em que nos forneceram termos com que pensar sobre o que acontece em nosso mundo.

Parte do poder dessas histórias deriva não só das palavras como das imagens que as acompanham. (TATAR, 2013, p.8)

Esta visão é inquietante e nos leva a questionar, então, como se dá a construção desses discursos particulares que tanto influenciam ou transformam nossa vida e nosso 
pensamento, a maneira de olharmos o mundo, de nos expressarmos e de gerarmos expectativas sobre nossas práticas sociais. Na sessão seguinte, faremos as análises das obras Cinderela Clássicos Ilustrados e Cinderela Surda quanto às categorias da Gramática Visual e da intertextualidade, buscando responder, de alguma maneira, a essa inquietação. Além disso, acredito que por meio da contextualização acima e dessas análises será possível desvelarmos o processo de produção dessas obras de modo satisfatório.

Antes, porém, vejamos na tabela abaixo a sistematização dessa contextualização, já direcionada pela análise discursiva:

\section{Tabela 1: Análise da Produção e da Distribuição-Consumo}

\begin{tabular}{|c|c|c|c|}
\hline & $\begin{array}{l}\text { CINDERELA } \\
\text { ORIGINAL }\end{array}$ & $\begin{array}{l}\text { CINDERELA } \\
\text { CLÁSSICA }\end{array}$ & CINDERELA SURDA \\
\hline PRODUÇÃO & $\begin{array}{l}\text { Processo: coletivo* } \\
\text { Público-alvo: Adultos } \\
\text { Status: entretenimento. } \\
\text { Substituía o lugar dos } \\
\text { filmes hoje. } \\
\text { Sem compromisso com a } \\
\text { moral. } \\
\text { Causava medo e } \\
\text { alumbramento. }\end{array}$ & $\begin{array}{l}\text { Processo: individual } \\
\text { Público-alvo: } \\
\text { crianças**usuárias da } \\
\text { língua portuguesa. } \\
\text { Status: pedagógico/ } \\
\text { educativo. } \\
\text { Possui compromisso com } \\
\text { a moral socialmente } \\
\text { aceita. Reflete a dicotomia } \\
\text { "o bem versus o mal'. } \\
\text { Causa comoção, } \\
\text { sentimento de justiça e } \\
\text { alumbramento. } \\
\text { Monolíngue }\end{array}$ & $\begin{array}{l}\text { Processo: coletivo } \\
\text { Público-alvo: comunidade } \\
\text { surda brasileira, crianças } \\
\text { ou jovens. Status: } \\
\text { pedagógico/ educativo. } \\
\text { Possui compromisso com } \\
\text { a moral aceita pela } \\
\text { comunidade surda e com } \\
\text { as suas lutas. } \\
\text { Reflete a história da } \\
\text { educação dos surdos. } \\
\text { Causa comoção, reflexão } \\
\text { histórica, sentimento de } \\
\text { justiça e alumbramento. } \\
\text { Bilíngue }\end{array}$ \\
\hline $\begin{array}{l}\text { DISTRIBUIÇÃO- } \\
\text { CONSUMO }\end{array}$ & $\begin{array}{l}\text { Modalidade: oral } \\
\text { Distribuição: por } \\
\text { contação de histórias, } \\
\text { "boca a boca". } \\
\text { Local: casas e bares } \\
\text { Processo: coletivo } \\
\text { Distribuição } \\
\text { complexa*** }\end{array}$ & $\begin{array}{l}\text { Modalidade: escrita e oral } \\
\text { Acesso: por leitura e } \\
\text { contação de histórias. } \\
\text { Local: casas; escolas; } \\
\text { bibliotecas; teatros. } \\
\text { Processo: coletivo } \\
\text { Distribuição complexa }\end{array}$ & $\begin{array}{l}\text { Modalidade:visualespacial } \\
\text { e escrita. } \\
\text { Acesso: por contação de } \\
\text { histórias em Libras e por } \\
\text { leitura. } \\
\text { Local: casas, escolas, e } \\
\text { comunidade surda. **** } \\
\text { Processo: coletivo } \\
\text { Distribuição complexa }\end{array}$ \\
\hline
\end{tabular}

\section{4) Análise de Cinderela Surda e de Cinderela Clássicos Ilustrados}

\section{1) Análise dos participantes}

(A) Participantes representados 


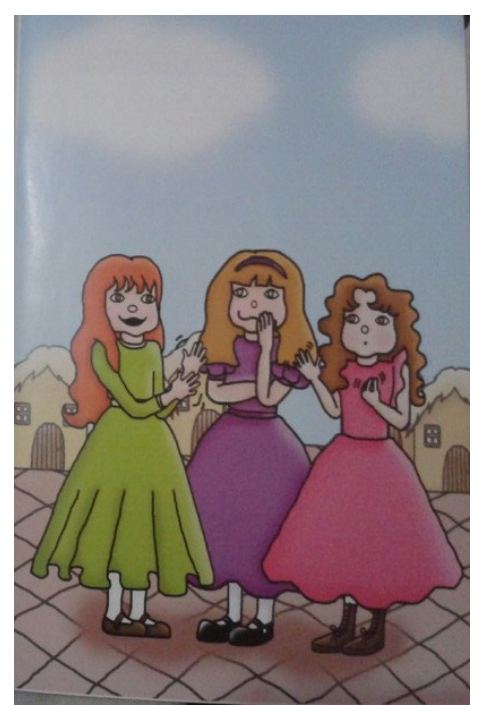

Figura A: p.07

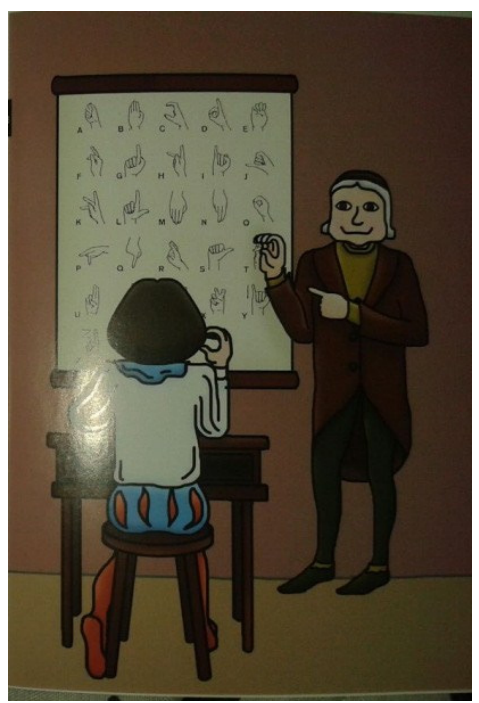

Figura B: p.09

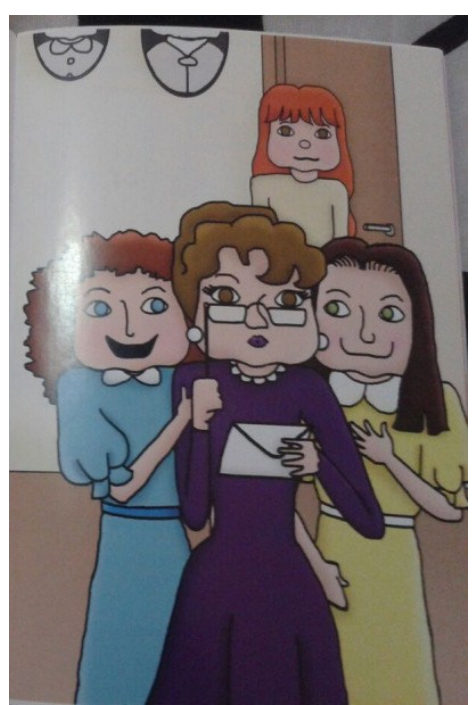

Figura C: p.15

Em Cinderela Surda os participantes representados são: (i) a comunidade surda, através dos personagens Cinderela (a primeira à esquerda - figura A) e de suas colegas surdas; do príncipe (assentado num banco - figura B), e do professor de LSF, fazendo alusão à figura do prof. ${ }^{\circ}$ Abade de L' Epée ${ }^{1}$; (ii) Paris (espaço); e (iii) os ouvintes, através dos personagens da madrasta e das irmãs (figura $\mathrm{C}$ ).

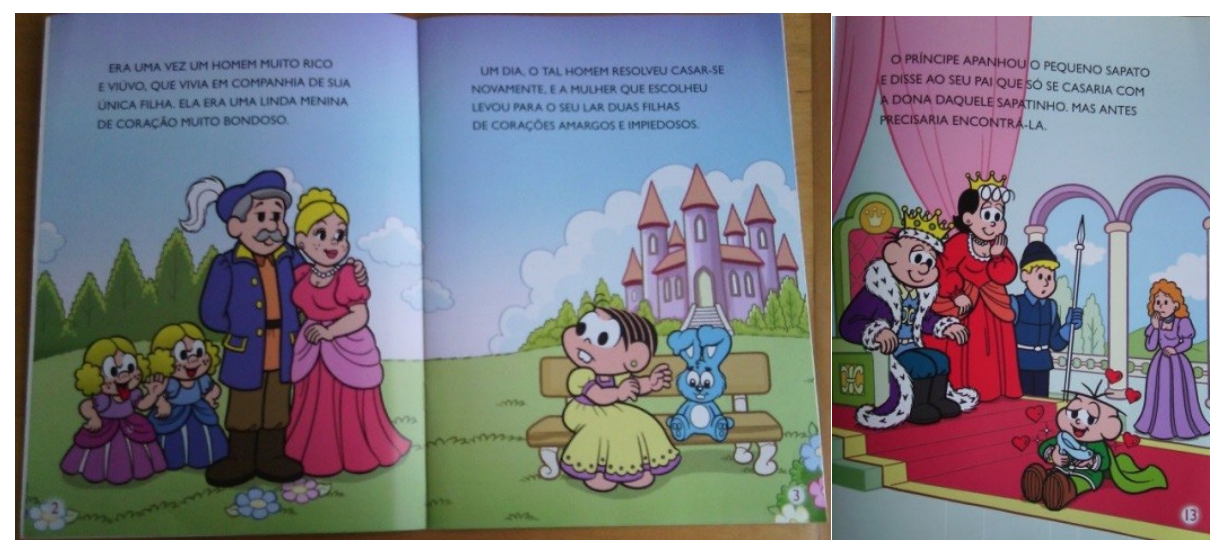

Figura A: p.2-3

Figura B: p.13

Em Cinderela Clássicos Ilustrados, os participantes representados são, conforme a figura A, (i) por alusão (recurso da intertextualidade), os personagens da Turma da Mônica: Mônica e seus pais, Seu Sousa e Dona Luísa; (ii) Sansão, o coelho da personagem Mônica (da Turma da Mônica), mas como personagem dessa história; (iii) a classe médiaalta, constituída por famílias nobres; e conforme a figura B, (iv) a família real; (v) o Palácio do Rei; (vi) o sapatinho de cristal; e (vii) Cebolinha e seus pais, Seu Cebola e Dona Cebola.

${ }^{1}$ O Prof. Abade de L' Epée foi o criador e defensor do Método Francês, conforme Lacerda (1998). 
(B) Participantes interativos

Em Cinderela Surda os receptores são, em especial, a comunidade surda usuária de signwriting, mas também leitores surdos não usuários, bem como leitores ouvintes que têm interesse em conhecer a cultura surda e/ou que já participam dela. Isto é subentendido tanto no corpo do livro, por meio da identificação do observador/leitor com os participantes representados, quanto na Apresentação, localizada na p.7 do livro, em que os autores esclarecem que este é bilíngue, com escrita de sinais, signwriting, e escrita em Português. Esta produção bilíngue é destinada a prover acesso à leitura também aos sujeitos surdos não usuários da escrita de sinais.

Em Cinderela Clássicos Ilustrados, os receptores são o público infantil no geral.

\section{2) Análise da composição espacial do significado}

(A) Dado/Novo

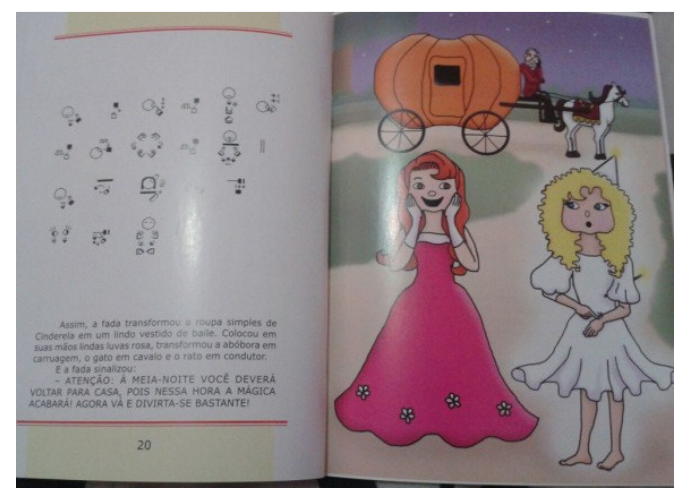

Figura A: p.20

Em Cinderela Surda: Se entendermos que a imagem deveria estar do lado esquerdo, como geralmente é concebido em análises dessa categoria, concluiremos que ela está localizada inadequadamente. Todavia, nossa análise pode partir de duas pressuposições: 1)Se partirmos da pressuposição de que o leitor é um sujeito surdo que sabe ler a escrita da língua de sinais, então podemos conceber que a informação conhecida (dada) e a informação desconhecida (nova) estão localizadas adequadamente, visto que essa escrita se comporta como uma informação principal. 2) Se partirmos da pressuposição de que o leitor é um sujeito surdo que não sabe a língua de sinais escrita, então, podemos considerar que as informações estão locadas inadequadamente, pois a informação dada será a imagem (que está à direita e teria que ser relocalizada para a esquerda) e a informação nova seria a escrita em língua portuguesa, ainda com as marcações em letras caixa alta (português transcrito), assim como já foi posta, considerando que para os surdos essa é a sua segunda língua. 
Em Cinderela Clássicos Ilustrados, não identificamos a categoria dado e novo. Os produtores optaram pela composição ideal/real.

(B) Ideal/Real

Em Cinderela Surda, o conteúdo é disposto da seguinte forma: estando o livro aberto, a lauda da esquerda sempre terá o conteúdo verbal, e a lauda da direita sempre terá o conteúdo não verbal (imagem), correspondente àquele. Esclarecido isto, sabemos que em sua composição não há as categorias ideal e real.

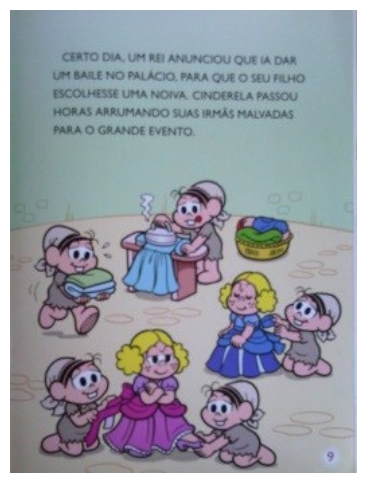

Figura A: p.09

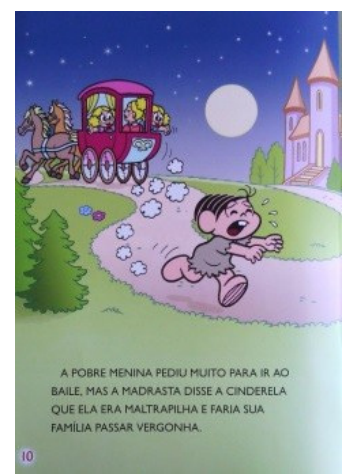

Figura B: p.10

Em Cinderela Clássicos Ilustrados, a estrutura do livro não é padronizada, ora a semiose verbal está na parte superior e o conteúdo não verbal está na parte inferior, ora são invertidas, como demonstrado nas figuras acima. Quantitativamente, há treze páginas com o conteúdo conforme a figura $\mathrm{A}$, e três páginas com o conteúdo conforme a figura B. Analisemos a partir dessas amostras: (i) Grupo representado pela figura A: o conteúdo não verbal, que se aproxima mais do concreto e que é mais detalhado, encontra-se adequadamente na posição inferior, em caráter de informação real, e o conteúdo verbal, mais distante do concreto, encontra-se adequadamente na posição superior, em caráter de informação ideal; (ii) Grupo representado pela figura B: a informação ideal (superior) encontra-se no lugar da informação real (inferior), e vice-versa.

Estas constatações nos levam a compreender que os produtores privilegiaram o conteúdo verbal em detrimento do conteúdo não verbal. Apesar de esta disposição espacial estar em consenso com a teoria da Gramática Visual, é relevante refletirmos sobre ela quando o público leitor for sujeitos surdos. Será que esta disposição dos elementos textuais favorece a leitura e compreensão da obra ou a disposição inversa favoreceria mais? Podemos refletir que ao se privilegiar o texto verbal, se concebe o uso do conteúdo não verbal (imagem) com a função de ilustrar o que o texto verbal narra, ou seja, o conteúdo principal está na narrativa verbal.

(C) Saliência/Projeção 
Esta categoria possui subcategorias, como primeiro e segundo planos; tamanho relativo; contrastes e tonalidades; cores; e formas. As análises a seguir buscarão identificá-las.
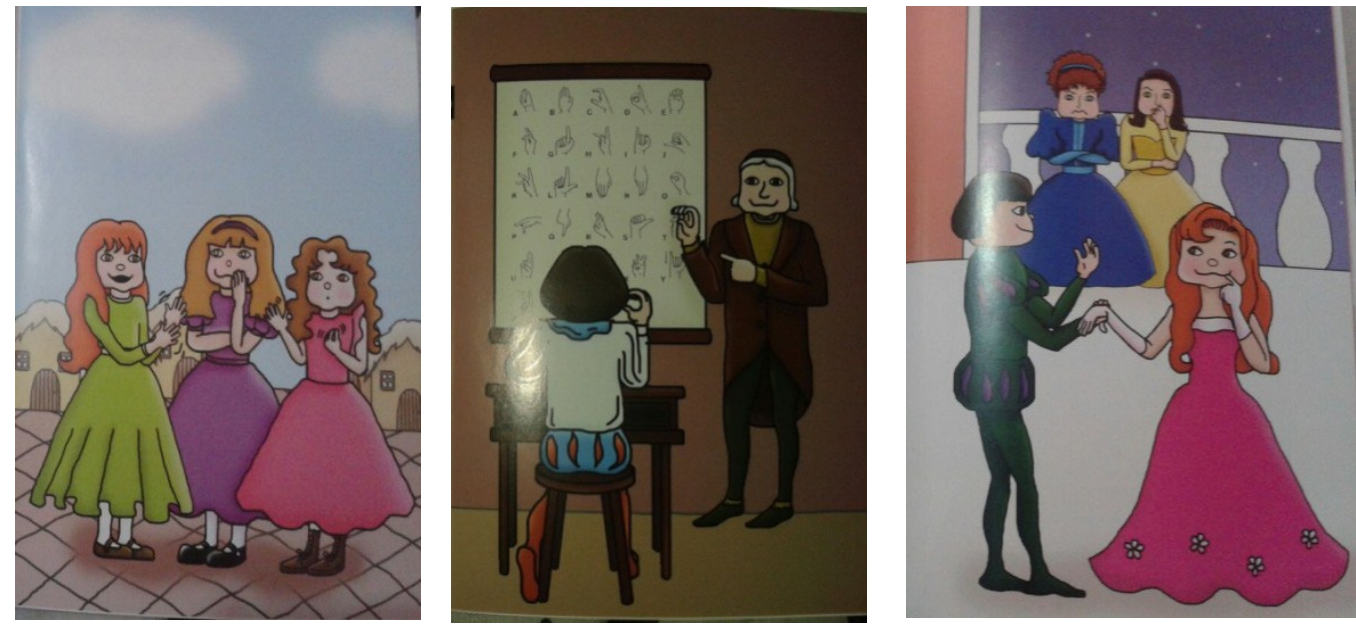

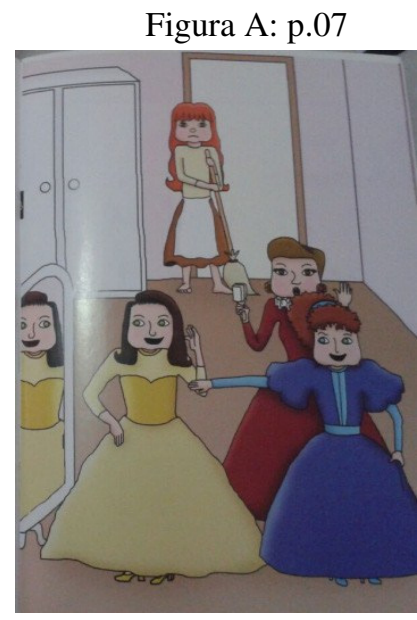

Figura D: p.15

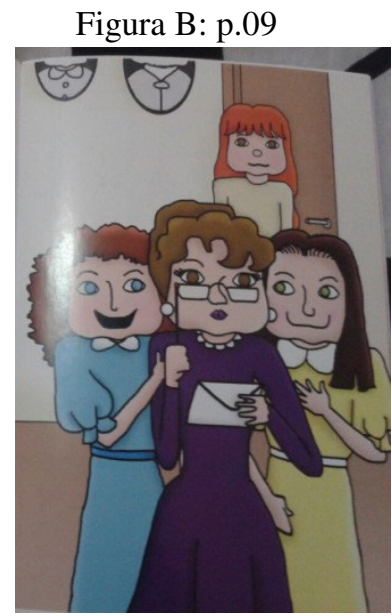

Figura E: p.15

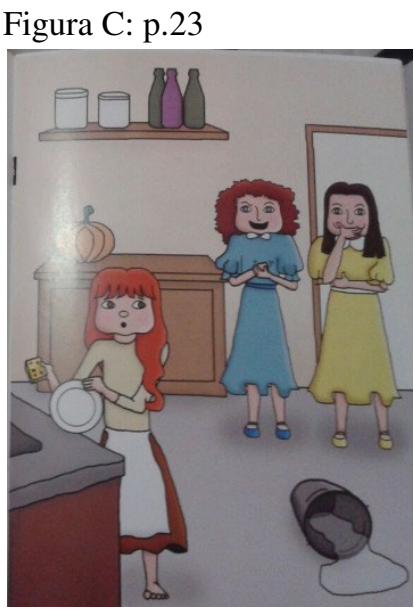

Figura F: p.13

Em Cinderela Surda: A partir das imagens selecionadas, é possível identificarmos, inicialmente, um aspecto relativo à construção da identidade surda em dois contextos, sendo que as imagens $\mathrm{A}, \mathrm{B}$ e $\mathrm{C}$, demonstram a identidade surda num contexto de reconhecimento da cultura surda, e as imagens D, E e F, demonstram a identidade surda num contexto de não reconhecimento. Façamos a análise da saliência e projeção separadamente para cada contexto representado:

$1^{\circ}$ ) Figuras A, B e C: nestas figuras, os personagens foram projetados de maneira simétrica, traçando uma linha horizontal (imaginária), em que não há julgamento de valor quanto à superioridade nem inferioridade ou subordinação, todos estão em relação de igualdade. As cores utilizadas reforçam essa ideia, visto que todos estão com vestimentas em cores fortes. Quanto à LS, há um destaque para ela, visto que nas três situações há a 
sua utilização pelos personagens, representada nas imagens, além de, nesta releitura Cinderela não perder um sapatinho de cristal (observem que na cena do baile, figura $\mathrm{C}$, nem é mostrado os péslsapatos dela), mas uma de suas luvas, ao sair correndo do baile. $\mathrm{Na}$ figura $\mathrm{C}$, os participantes que não partilham da mesma cultura, estão posicionados em segundo plano, tanto por estarem na parte de trás (espaço), quanto pelo tamanho reduzido (tamanho relativo e contraste).

$2^{\circ}$ ) Figuras D, E e F: Quando Cinderela está em meio à sua família, sua posição é sempre a de subordinada, inferior, nunca estando simetricamente ao lado dos demais participantes, mas atrás deles, numa posição mais distante, com zoom menor (tamanho relativo e contraste) e em segundo plano. Suas expressões faciais também demonstram seu "deslocamento" em relação aos outros participantes. As cores de sua vestimenta são sempre opacas, em contraposição com as cores fortes das vestimentas dos demais, o que lhe confere o valor de "inferioridade e pobreza", ou nos termos da literatura, maltrapilha. Diferentemente das figuras A, B e C, aqui não se encontra representada a Língua de Sinais, mas a língua oral na modalidade escrita, por meio da figura $\mathrm{E}$, em que há o elemento "carta". Por fim, na figura F, apesar de espacialmente Cinderela estar posicionada à frente, o direcionamento do seu olhar é para trás, onde se encontram as irmãs, que com expressões faciais imperativas e ao mesmo tempo de zombaria, conferem à Cinderela subalternidade.

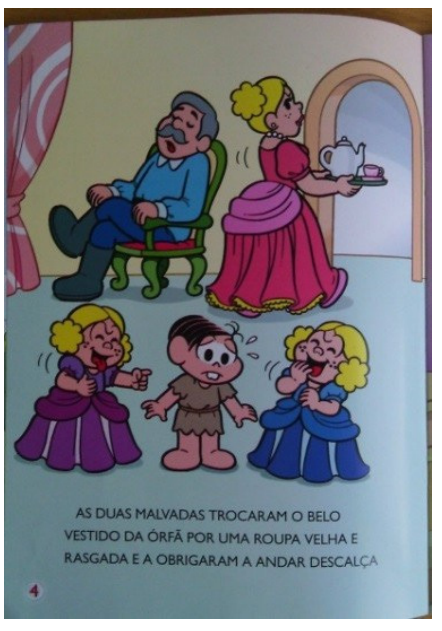

Figura A: p.04

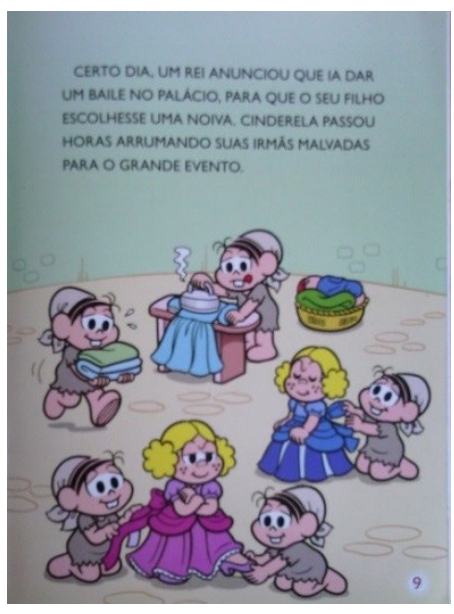

Figura B: p.09

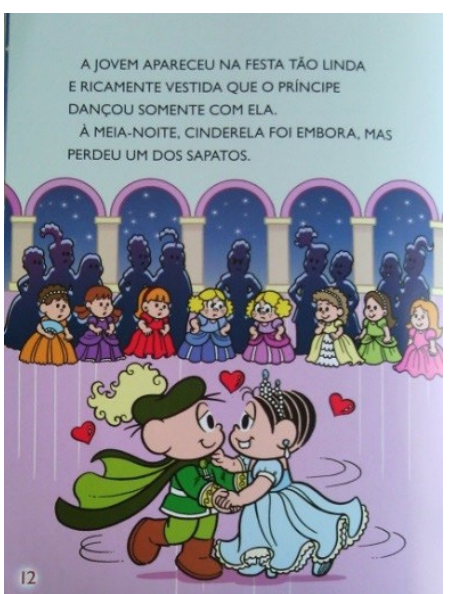

Figura C: p.12

Em Cinderela Clássicos Ilustrados, na figura A temos a representação imagética de dois planos, o superior e o central. No superior há o pai e a madrasta da Cinderela, ambos em segundo plano, estando a figura do pai indiferente ao que ocorre no plano central, dando a entender que nada ele está vendo, e a figura da madrasta diretamente conectada pela direcionalidade do olhar (olhar de canto de olho) ao plano central, demonstrando sua consciência da 'realidade'. No plano central, que é o primeiro plano espacialmente, temos a Cinderela posicionada entre as duas irmãs, em posição, portanto, de opressão. Contribuindo para tal, há também as expressões faciais de tristeza, de Cinderela, e de sarcasmo e zombaria, das irmãs. Os tons utilizados na vestimenta destas 
são cores fortes e na da Cinderela, é uma cor nude/opaca, que se repete em outras cenas, como na figura B. Nesta, Cinderela está representada em vários momentos de sua atividade doméstica, sempre servindo às irmãs. Por fim, na figura $\mathrm{C}$, a sociedade é representada em segundo plano, num tamanho bastante reduzido, conferindo destaque aos personagens principais, a Cinderela e o príncipe, que estão em primeiro plano, expressivos fisicamente e facialmente de maneira positiva - estado de encantamento - e vestidos de maneira "digna e nobre", utilizando cores fortes, além da coroa na cabeça da Cinderela, salientando a representação social de nobreza.

(D) Enquadramento

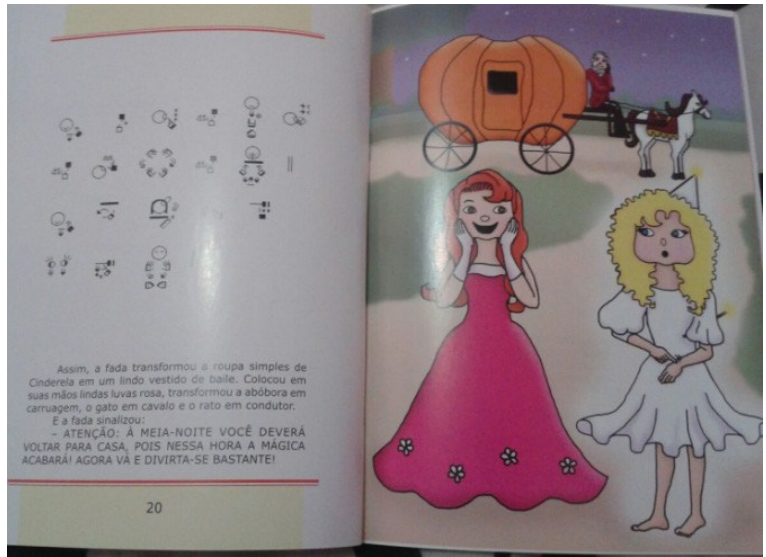

Figura A: p.20-21

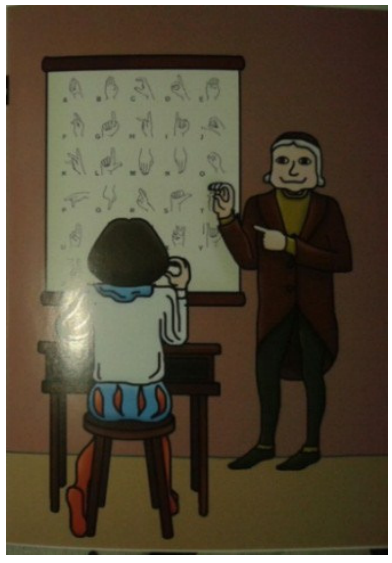

Figura B: p.09

Em Cinderela Surda, a organização semiótica permite que as semioses verbais não disputem espaço com a semiótica não verbal. Assim, temos o enquadre em relação à sequência da narrativa não verbal no que tange à paginação, e o enquadre contido em cada página destinada a esse conteúdo não verbal. Quanto ao primeiro, temos o enquadramento página por página, definido pela funcionalidade de cada página e demonstrado pela linha divisória do próprio livro e pela área ocupada pela imagem - cada imagem tem início e fim numa única página, não ultrapassando esse limite. Quanto ao segundo, temos os enquadramentos formados pela paisagem e pela disposição dos personagens neste espaço. $\mathrm{Na}$ figura A, por exemplo, identificamos dois enquadres através do traçado do caminho de terra, cuja forma é em "I". Cinderela e sua fada madrinha se encontram no caminho vertical e, no caminho horizontal, encontramos a carruagem, o cavalo e o cocheiro, com partida espacialmente orientada para o sentido leste. Na figura $\mathrm{B}$, identificamos outro modo de enquadre, traçado pelo quadro branco - instrumento de trabalho do professor em que se focaliza (enquadra) o alfabeto da língua de sinais francesa. Este enquadre concede visibilidade à língua de sinais e, por conseguinte, à cultura surda. 


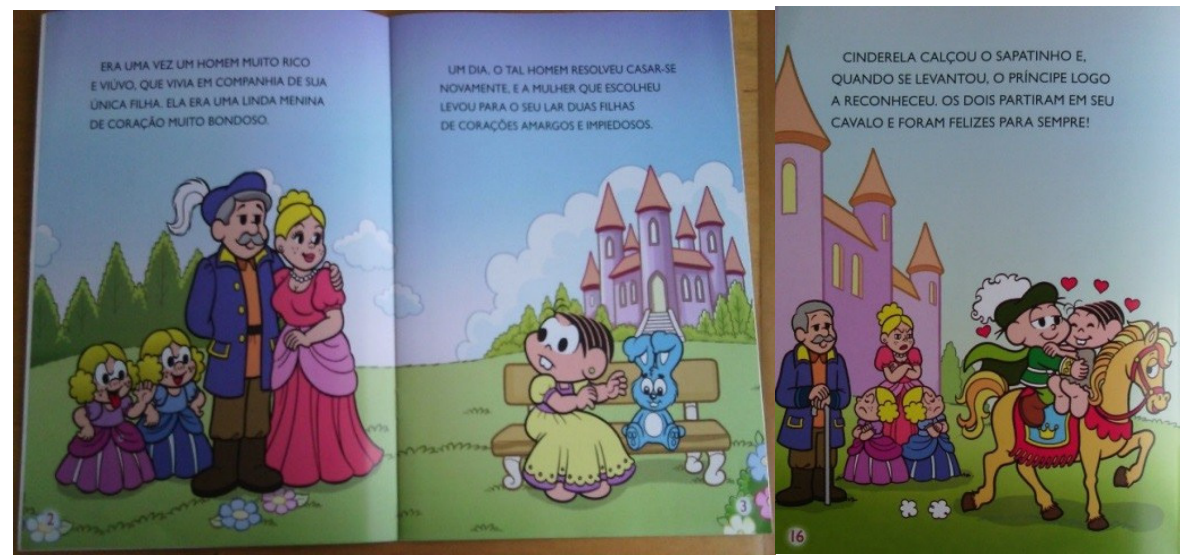

Figura A: p.2-3

Figura B: p.16

Em Cinderela Clássicos Ilustrados, há diferentes aplicações de enquadre, como podemos ver nos dois exemplos acima. Na figura A, foram utilizadas as duas páginas, lado a lado, para compor uma mesma cena. Esta extensão de cena não é recorrente nesta obra, visto que majoritariamente as cenas são dispostas como na figura B, "comprimidas" em uma única página. Além disso, na figura $\mathrm{B}$, como exemplo de outros traços de enquadre, temos a presença de uma linha divisória se observarmos as sombras do cavalo em relação às sombras da família da Cinderela. O cavalo está mais à frente, ao lado direito e direcionado "para fora", já a família está recuada para trás, à esquerda e em outro alinhamento.

\section{3) Análise da Intertextualidade}

Em Cinderela Surda, a intertextualidade é identificada por meio do elemento "discurso". Em nenhum momento há um discurso direto ou explícito fazendo remissão a obra anteriores, em exceto à obra base da releitura - Cinderela - porém, há elementos da intertextualidade constitutiva, que é aquela em que um texto incorpora outro sem marcações explícitas. Este elemento é mais recorrente nas páginas iniciais, quando é contextualizada a identidade surda do príncipe e também de Cinderela.

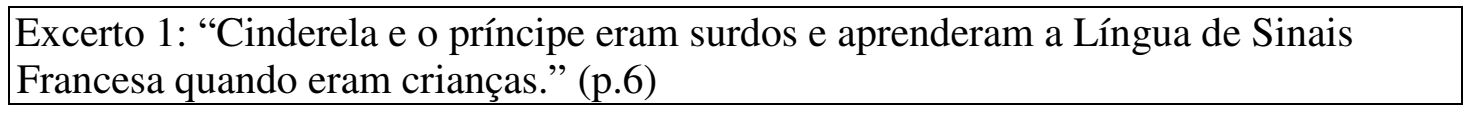

Neste primeiro excerto, referente à primeira página da história, já é possível o leitor construir uma correlação entre o enredo de Cinderela e a história da educação dos surdos, caso ele a conheça, por meio da informação de que a língua de sinais aprendida é a francesa.

Em seguida, temos os seguintes trechos:

Excerto 2: "Cinderela ... aprendeu a Língua de Sinais Francesa com a comunidade de surdos nas ruas de Paris." (p.8) 
Excerto 3: "O rei e a rainha contrataram o mestre L'Epeé para ensinar a Língua de Sinais Francesa ao príncipe herdeiro do trono." (p.8)

Com a leitura destes dois trechos, o leitor tem a confirmação de que a história de Cinderela Surda se trata de uma releitura que contempla os temas identidade e cultura surda numa perspectiva histórica da educação dos surdos. Aliado aos textos, há a ilustração, localizada na página 9 , em que temos a figura do príncipe na condição de aluno, e a figura de um professor de LSF, representando o prof. ${ }^{\circ}$ Abade de L'Epeé, criador e defensor do Método Francês.

Assim, aliando esses trechos ao título de capa - Cinderela Surda - talvez já possamos identificar um cruzamento de discursos: o discurso da comunidade surda e o discurso literário de Cinderela, o qual corresponde ao discurso moral da sociedade ocidental. Podemos considerar que a utilização da intertextualidade é o que possibilitou a releitura de Cinderela sob um viés histórico da educação dos surdos, gerando, pois, uma transformação no discurso da Cinderela Clássica e propiciando uma mudança social (na ordem da distribuição-consumo).

Como visto no tópico 4.1 "Participantes representados", em Cinderela Clássicos Ilustrados há intertextualidade nas dimensões dos elementos "gênero" e "discurso", recorrendo-se à utilização da figura de alguns personagens da HQ da Turma da Mônica. Ao se constituir dessa mescla, a obra faz remissão à relação existente entre os personagens Mônica e Cebolinha, agora representados pelos personagens Cinderela e príncipe. Na HQ, Mônica e Cebolinha se gostam e, em sua versão para o público jovem - Turma da Mônica Jovem - eles se tornam um casal de namorados. Em Cinderela, por sua vez, há a construção de uma relação dessa mesma natureza, a amorosa, com os personagens Cinderela e príncipe. Tal constituição textual gerou uma duplicidade de leitura e de interpretação para os leitores que possuem conhecimento prévio da obra Turma da Mônica. Além disso, Cinderela tem um bicho de pelúcia, não nomeado, mas que é igual a Sansão, o coelho da Mônica.

Diante das análises acima, vejamos a sua sistematização na tabela abaixo: Tabela 2: Análise da Semiótica nos modos verbal e não verbal

\begin{tabular}{|c|c|c|}
\hline & CINDERELA CLÁSSICA & CINDERELA SURDA \\
\hline \multirow{5}{*}{$\begin{array}{l}\text { PARTICIPANTE } \\
\text { REPRESENTADO }\end{array}$} & Ouvintes & Comunidade surda (Minoria social) \\
\hline & Classe média-alta & Ouvintes não usuários de LS \\
\hline & Família Real (nobreza) & Família Real (Nobreza) \\
\hline & Sapatinho de Cristal & Luvas \\
\hline & & Paris \\
\hline \multirow{2}{*}{$\begin{array}{l}\text { PARTICIPANTE } \\
\text { INTERATIVO }\end{array}$} & Ouvintes Crianças & Leitores usuários de signwriting \\
\hline & & Comunidade Surda \\
\hline \multirow{2}{*}{ DADO/NOVO } & & Pessoas de todas as faixas etárias \\
\hline & & $\begin{array}{l}\text { Dado: texto em signwriting Novo: } \\
\text { ilustracão }\end{array}$ \\
\hline \multirow{3}{*}{ REAL/IDEAL } & Em maior porcentagem $(77 \%)$ & \\
\hline & Real: ilustração & \\
\hline & Ideal: Texto em português & \\
\hline
\end{tabular}




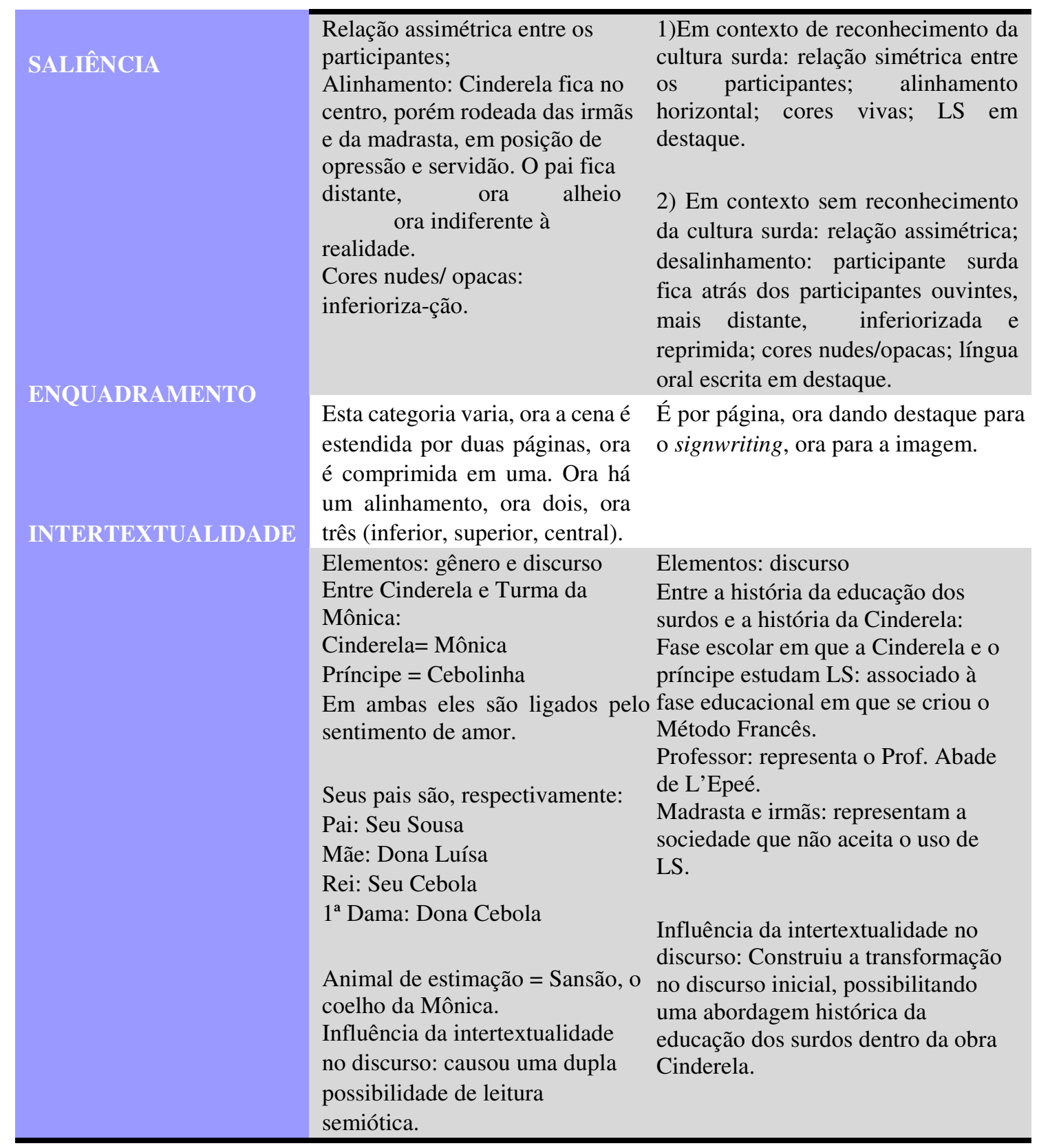

\section{5) Contribuições da análise para a Educação Bilíngue para Surdos}

Nesta fase, após conhecermos a contextualização das obras e as análises acima, é relevante abordarmos esse conhecimento a partir da noção de produção e consumo da ADC, aplicada ao ensino. Creio que podemos refletir que ambas as obras foram produzidas a partir de motivações e pretensões, seguramente socioculturais, ou seja, nos princípios da $\mathrm{ADC}$, foram produzidas de forma particular em contextos sociais específicos. Baseadas na Semiótica Social, Santos e Pimenta (2014) apontam, em relação à representação, que 
o interesse guia a seleção, ou seja, a escolha de uma representação é pautada por um aspecto suficientemente representativo do objeto em um dado contexto. Ao escolher uma representação, o ator social o faz com referência ao que, no seu entendimento, pode ser considerado o modo mais apto e plausível naquele contexto e naquela cultura. (SANTOS E PIMENTA, 2014, p.301)

Pelas análises dos participantes representados e interativos, pudemos observar que no processo de produção de Cinderela Surda se pretendeu uma releitura que trabalhasse com os temas identidade e diferença (KARNOPP, 2006), por meio do resgate histórico da educação de surdos. Em comparação com Cinderela Clássicos Ilustrados, foram acrescentadas informações da história de vida dos personagens principais, Cinderela e o príncipe, como o contexto em que eles estudaram LSF, caracterizando-os com a cultura e identidade surda e colocando-os como participantes ativos delas. Tal aspecto nos faz refletir quanto à motivação desta produção, como sendo a criação de produtos que registrem, contemplem e divulguem a história e a cultura dos surdos, e quanto à sua pretensão, fator ligado à distribuição-consumo, como sendo a divulgação e distribuição desse discurso particular, por exemplo, em escolas para acesso pela própria comunidade surda e por toda a sociedade que compartilha desse mesmo espaço. Para Karnopp (2006),

A literatura surda começa a se fazer presente entre nós, se apresentando talvez como um desejo de reconhecimento, em que busca 'um outro lugar e uma outra coisa'. A literatura do reconhecimento é de importância crucial para as minorias linguísticas que desejam afirmar suas tradições culturais nativas e recuperar suas histórias reprimidas. (KARNOPP, 2006, p.100)

A inserção dessa literatura no ambiente escolar não objetiva instaurar uma divisão entre as literaturas, pelo contrário - daí se valorizar a literatura clássica por meio do acesso a ela em produções voltadas para o público surdo (como ocorrem em DVDs de contos com interpretação em LS), mas também atribuindo a mesma uma releitura sob abordagem da cultura e identidade surda.

Para a ADC, os textos podem ser consumidos de maneiras diferentes a depender do contexto e do trabalho interpretativo que se aplica. Neste sentido, os aprendizes surdos podem ter acesso tanto à obra Cinderela Clássica Ilustrada quanto à obra Cinderela Surda, a depender do objetivo e do empenho do professor em trabalhar as obras adequadamente, de maneira a dar acesso aos seus sentidos, a saber, a construção de sentido por meio da relação entre os modos semióticos envolvidos, o verbal e o não verbal.

Como contribuição, deixamos a sugestão de os professores, ao selecionarem obras literárias ou após esta seleção, realizarem uma análise prévia baseada na Gramática Visual e talvez, a depender dos objetivos pedagógicos, em algumas categorias da ADC, a fim de identificar o potencial semiótico e discursivo dessas obras e de, a partir deste, construir uma proposta e/ou dinâmica de aula que o contemple. Ao nos basearmos na riqueza da análise acima, inferimos que a aula de literatura em contexto de educação bilíngue para surdos pode se beneficiar desses pressupostos teóricos, fomentando um ensino de leitura literária que reconhece o seu caráter multimodal. 
Além disso, em contexto de educação de surdos, o professor, ao selecionar obras literárias como Cinderela Clássicos Ilustrados, deve ter consciência das necessidades prováveis dos aprendizes, como a tradução da obra em LS e a explicação de referenciais de mundo que estão presentes na narrativa de maneira implícita ou explícita e que interferem nas possibilidades de leitura, mas que alguns alunos podem não identificar por não terem tido acesso prévio a estes.

Um exemplo claro de um tipo de conhecimento implícito é o caso de intertextualidade encontrado em Cinderela C. I. : nesta releitura, a ilustração foi feita com alguns personagens da Turma da Mônica e essa seleção não foi aleatória, a Cinderela e o príncipe são, respectivamente, a Mônica e o Cebolinha e é sabido por seus leitores que existe entre eles algum tipo de "atração", um "afeto ou amor", tanto que na narrativa de Turma da Mônica Jovem esses personagens mantêm um relacionamento amoroso. Assim, para a promoção dessa leitura, o professor de surdos precisaria investigar até onde seus alunos possuem esses conhecimentos prévios e adotar uma metodologia que responda às demandas identificadas.

A produção de Cinderela Surda se coloca justamente nesse ínterim, em que surgem barreiras como a linguística e a cultural, possibilitando outra abordagem de ensino: aquela que é pensada e produzida para os aprendizes surdos. Em se objetivando um ensino bilíngue e multicultural para surdos, o consumo de obras produzidas para esse público configura-se como altamente significativo e produtivo, além de necessário, do ponto de vista da inserção da cultura surda no ambiente escolar. Em Cinderela Surda, também há demandas de conhecimentos prévios, como a história da educação dos surdos e da legalização do uso de língua de sinais, mas é previsível que os sujeitos que se reconhecem e se projetam na cultura surda os tenham, além de a própria narrativa já suscitar a discussão sobre os mesmos.

Referindo-se à experiência literária, no geral, Tatar (2013) reflete que:

Para nós, também, as histórias são irresistíveis, pois oferecem oportunidades para falar, debater, deliberar, tagarelar e conversar fiado interminavelmente, como faziam as velhas comadres de quem, ao que se diz, essas histórias vieram. E a partir do emaranhado dessa conversa e tagarelice, começamos a definir nossos próprios valores, desejos, apetites e aspirações, criando identidades que nos permitirão produzir finais para sempre felizes para nós e para nossos filhos. (TATAR, 2013, p.17)

Dessa mesma forma, numa sala de aula, a inserção da literatura surda pode ser uma oportunidade para falar e debater sobre muitos temas relevantes para a construção do saber e da cidadania, além de ser também um espaço para a apreciação da leitura literária como arte e cultura. Os professores de surdos podem fazer algumas reflexões quanto à inserção da literatura clássica e da literatura surda na escola, como "Será que os alunos têm acesso a estas literaturas fora do ambiente escolar?"; "Como seria uma aula pensada para esse público, que utilizasse materiais também produzidos para eles?"; "Com qual abordagem eu conseguirei explorar de maneira satisfatória as potencialidades multimodais e multissemióticas desses materiais?"; "Como eu posso especializar o meu 
trabalho pedagógico para esse público?”, entre outras. Estas questões para reflexão sobre o trabalho em sala de aula se apresentam como um dos caminhos para se pensar nesse ensino, o qual se configura de modo singular e especializado.

$\mathrm{Na}$ sessão seguinte, faremos as considerações finais buscando passear pelas análises aqui realizadas e por sua contribuição para a educação bilíngue de surdos.

\section{6) Considerações finais}

Por meio da análise da composição espacial do significado, pudemos observar que por trás de uma produção literária há todo um trabalho que visa construir sentido por meio dos modos semióticos verbal e não verbal. Nas duas obras, cada princípio da composição foi contemplado em algum nível, ora mais abrangente e detalhado, ora menos, mas sempre corroborando a leitura e interpretação das obras dentro do discurso particular e do recorte de tempo, espaço e cultura proposto por cada uma.

Identificamos também que a relação entre esses modos semióticos constroem sentido amplificado, ou seja, quando o leitor realiza uma leitura que contempla as relações entre as semioses existentes na obra, há acesso a uma leitura interpretativa exploratória, mais abrangente e mais significativa. As tabelas 1 e 2, por meio da sistematização de todos princípios e categorias analisados, nos revelam exatamente a riqueza e a funcionalidade dos modos semióticos em integração. Um exemplo é o princípio da Saliência/Projeção que se mostrou como um dos mais significativos nas duas obras.

Em Cinderela Surda, o modo semiótico verbal em integração com o modo semiótico não verbal denuncia um contexto de conflito e de busca por reconhecimento identitário e social dos sujeitos surdos e, enquanto Saliência, o modo não verbal se comporta como um intensificador de sentido, por um lado demarcando a segregação sofrida por Cinderela quando encontrava-se num contexto social ausente de reconhecimento da cultura surda e, por outro lado, demarcando a simetria entre Cinderela e os demais personagens quando ela se encontrava num contexto de reconhecimento da cultura surda.

Em Cinderela Clássicos Ilustrados, a Saliência/Projeção também se apresentou como recurso essencial na construção de sentido, revelando a subordinação e subalternidade conferida à Cinderela, a falta de consciência e/ou a passividade do pai em relação aos sofrimentos da filha, o comportamento maldoso das irmãs e a consciência dos fatos por parte da madrasta. A disposição dos personagens nos primeiros e segundos planos, as cores conferidas às suas vestimentas, as expressões faciais e corporais, tudo isto conferiu sentido à construção narrativa de cada personagem.

Creio que a análise realizada é de grande valia, antes de tudo, por trazer à baila a existência da cultura surda e por demonstrar que a sua produção possui motivações sociais, culturais e políticas relevantes e dignas de serem inseridas no contexto escolar e, por fim, por demonstrar mais uma vez que a utilização dos modos semióticos em 
integração confere consistência ao discurso particular em jogo e possibilita uma experiência de leitura ímpar, geradora de diversos tipos de reação.

Como Ribeiro (2014, p.107) diz: "tudo significa muito para o aluno Surdo: a cor, o tamanho, a fonte utilizada, as imagens. Este tentará de todo modo relacionar a imagem à parte escrita, já que ele só possui memória visual." Assim, o aluno Surdo tem um tipo de reação ao ler Cinderela Clássica Ilustrada e outro tipo de reação ao ler Cinderela Surda. Cada leitura irá lhe propiciar uma experiência e uma possibilidade de diálogos, reflexões, inferências e prazeres distintas.

\section{Referências}

BAKTHIN, M. Estética da criação verbal. Tradução M. E. G. Pereira. 2ed. São Paulo: Martins Fontes, 1997, p. 277-326.

FAIRCLOUGH, Norman. Discurso e Mudança Social. Coordenação de Tradução Izabel Magalhães. Brasília: Editora Universidade de Brasília, 2008, p.101- 105. (reimpressão)

KARNOPP, Lodenir. Literatura Surda. Educação de Surdos e Língua de Sinais. ETD - Educação Temática Digital, Campinas, v.7, n.2, p.98-109, jun. 2006.

KRESS, Gunther; VAN LEEUWEN, Theo. Reading images: the grammar of visual design. 2ed. London, New York: Routledge, 2006. 304p.

KRISTEVA, Julia. Bakhtine, le mot, le dialogue et le roman. Critique. Revue générale de publications. Paris, vol.29, fascículo 239, p.438-465, abr. 1967.

LACERDA, Cristina B. F. Um pouco da história das diferentes abordagens na educação dos surdos. Caderno CEDES, vol.19, n.46, pp.68-80, 1998. Disponível em: <http://dx.doi.org/10.1590/S0101-32621998000300007> Acesso em: 28 jun. 2016.

MAROUN, Cristiane R. G. B. A multimodalidade textual no Livro Didático de Português. Universidade de Brasília: Instituto de Letras, 2006, p.61-64. Dissertação de Mestrado.

RIBEIRO, Álvaro G. L. Materiais Didáticos de Português para Surdos brasileiros: Uma análise aplicada ao contexto de Educação Bilíngue no DF. Universidade de Brasília: Instituto de Letras, 2014, p.107. Dissertação de Mestrado.

SANTOS, Záira B.; PIMENTA, Sônia M. O. Da semiótica Social à Multimodalidade: a orquestração de significados. In: Cadernos de Semiótica Aplicada, v12, n2, 2014, p.295-324.

SILVEIRA, Carolina HESSEL; KARNOPP, Lodenir; ROSA, Fabiano. Cinderela Surda. 3ed. Canoas: Ed.ULBRA, 2011, 36p. 
SOUSA, Mauricio de. Cinderela. Coleção Clássicos Ilustrados. SP: Girassol Brasil Edições Ltda. 2008, 16p.

Contos de Fadas. Introdução e Notas de Maria Tatar. Tradução de Maria Luiza Borges. 2 ed. RJ: Zahar, 2013, p.452.

VIEIRA, Josenia Antunes; FERRAZ, Janaina de Aquino. Percursos e avanços do texto multimodal: novas perspectivas na contemporaneidade. Revista Discursos Contemporâneos em Estudo, Brasília, vol.1, n.1, p.9-23, 2011. 